Kumawula, Vol. 3, No.2, Agustus 2020, Hal 358 - 366 DOI: https://doi.org/10.24198/kumawula.v3i2.27195

ISSN 2620-844X (online)

Tersedia online di http://jurnal.unpad.ac.id/kumawula/index

\title{
PEMBERDAYAAN MASYARAKAT DALAM UPAYA UNTUK MENINGKATKAN TARAF KEHIDUPAN MELALUI INOVASI PRODUK BEBAS BAHAN KIMIA BERBAHAYA DI DESA PAMULIHAN KABUPATEN SUMEDANG
}

\author{
Hilmiana $^{1 *}$, Desty Hapsari Kirana ${ }^{2}$, Cattleya Rejito ${ }^{3}$ \\ ${ }^{1,2,3}$ Universitas Padjadjaran \\ *hilmiana@fe.unpad.ac.id
}

\begin{abstract}
ABSTRAK
Desa Pamulihan adalah desa yang terletak di Kecamatan Pamulihan, Kabupaten Sumedang yang berstatus desa dengan klasifikasi sebagai desa mandiri. Desa Pamulihan menghasilkan kerajinan tangan dari kayu yang memiliki kualitas sangat tinggi, seperti wayang golek dan dibidang pertanian yang mengolah talas, golden berry, manggis dan jambu biji. Potensi Desa Pamuliha yang tinggi dapat membuat masyarakat lebih sejahtera di daerah ini. Namun, masih ada kekurangan modal untuk dapat mengembangkan bisnis mereka dan terbatasnya kreativitas masyarakat dalam mengembangkan produk masih menjadi masalah utama di Desa Pamulihan ini. Selain itu, kurangnya pengetahuan untuk dapat melakukan kegiatan pemasaran dan penjualan masih belum dipahami dengan baik oleh masyarakat setempat. Tentu saja masalah ini telah menjadi fokus utama akademisi untuk melakukan kegiatan pelatihan yang dianggap mampu memaksimalkan potensi yang ada di Desa Pamulihan. Berdasarkan kondisi yang terjadi di lapangan, 3 bentuk pelatihan dilakukan untuk meningkatkan potensi yang ada di Desa Pamulihan. Pelatihan ini termasuk pelatihan pemasaran digital untuk produk kerajinan kayu dan pelatihan dalam pengembangan produk inovatif yang terbuat dari bubuk talas dan teh yang terbuat dari daun berry.
\end{abstract}

Kata kunci: Inovasi Produk, Pemasaran Digital, Media Sosial

\begin{abstract}
Desa Pamulihan is a village located in the Pamulihan sub-district of Sumedang Regency which has a status as a self-supporting village. Desa Pamulihan produces handicrafts from wood that have very high quality, such as wayang golek, and plants such as taro, golden berries, mangosteen and guava crystals in the field of agriculture. The high potential of Desa Pamulihan can make the people in this area more prosperous. However, there is still a lack of capital to be able to develop their business and the limited creativity of the community in developing products is still a major problem in Desa Pamulihan. In addition, the lack of knowledge to be able to carry out marketing and sales activities is still not well understood by the local community. Of course, this issue has become the main focus of academics to carry out training activities that are considered capable of maximizing the potentials that exist in Desa Pamulihan. Based on the conditions occurring in the field, 3 forms of training were carried out to increase the existing potential in Desa Pamulihan. These trainings include digital marketing training for wood craft products and training in the development of innovative products made from taro powder and tea made from berry leaves.
\end{abstract}

Keyword: Product Innovation,, Digital Marketing, Social Media 


\section{PENDAHULUAN}

Ekosistem bisnis yang sukses didefinisikan oleh usaha-usaha yang bekerja secara kooperatif dan kompetitif untuk mendukung produk-produk baru, memuaskan kebutuhan pelanggan, dan akhirnya memasukkan inovasi pada proses bisnisnya (Moore, 1993: 76). Salah satu cara untuk memuaskan kebutuhan pelanggan adalah dengan menghasilkan produk yang bernilai dan mampu membawa manfaat bagi penggunanya. Agar produk hasil bisnis tersebut dapat diketahui oleh para calon pembeli, dibutuhkan sarana atau media yang tepat dalam memasarkan produk tersebut. Salah satu metode pemasaran yang saat ini lazim digunakan karena rendah biaya, efektif dan efisien adalah proses pemasaran dengan menggunakan teknologi digital. Teknologi digital telah digunakan untuk dapat membantu proses pembangunan di berbagai bidang seperti pada bidang pendidikan melalui pembelajaran jarak jauh, pemerintahan melalui e-government, inklusi keuangan melalui fin-tech, dan pengembangan UMKM melalui pengembangan e-commerce (Rencana Pembangunan Jangka Menengah, 2020-2024). Literatur menunjukkan bahwa digitalisasi dalam berbagai bentuk berhubungan positif dengan pertumbuhan usaha kecil, kinerja dan daya saing (Taiminen \& Karjaluoto, 2015). Pemasaran digital dan media sosial memberikan peluang bagi usaha kecil untuk menarik pelanggan baru dan menjangkau pelanggan yang sudah ada secara lebih efisien. Pepatah, "Jika sebuah perusahaan tidak dapat ditemukan di Google, itu tidak ada" tampaknya melambangkan perilaku konsumen saat ini. Jelas bahwa pemanfaatan saluran digital penting untuk mengembangkan merek dan dapat menjadi kemajuan yang harus diikuti oleh UKM agar tetap kompetitif dan tumbuh.

Secara definisi pemasaran digital adalah pendekatan baru untuk pemasaran yang didorong oleh elemen digital (Taiminen \& Karjaluoto, 2015). Media sosial telah menjadi bagian penting dari komunikasi pemasaran dan branding bisnis (Bruhn et al., 2012). Misalnya Facebook telah menjadi saluran penting dalam melibatkan konsumen dan menciptakan kesadaran merek (Malhotra et al., 2013). Media sosial dapat menawarkan saluran ekstra untuk berkomunikasi dengan pelanggan, tetapi juga dapat dikembangkan sebagai layanan itu sendiri (Bouwman et al., 2018)

Media sosial sebagaimana didefinisikan oleh Kaplan dan Haenlein (2010, p. 61) adalah "sekelompok aplikasi berbasis Internet yang dibangun di atas fondasi ideologis dan teknologi Web 2.0 yang memungkinkan adanya pembuatan dan pertukaran konten oleh para 
pengguna”. Media sosial telah mengubah cara orang berinteraksi satu sama lain. Dengan mengeksploitasi fungsionalitas sosial media, pengusaha dapat menggunakannya untuk mengelola aktivitas bisnis mereka, contohnya pada aspek pemasaran (Alalwan, et al., 2017; Misirlis \& Vlachopoulou, 2018). Seperti dilansir Lister (2018), lebih dari 50 juta bisnis menggunakan halaman bisnis Facebook. Termasuk 2 juta diantaranya yang menggunakannya untuk iklan langsung. Tren serupa dapat diamati di platform media sosial dominan lainnya seperti Instagram, di mana separuh pengguna mengikuti halaman bisnis (Pickard-Whitehead, 2018). Setelah preferensi konsumen dipaham dengan baik, sebuah bisnis dapat menggunakan media sosial sebagai metode yang efektif untuk berkomunikasi dengan pelanggan serta dapat digunakan untuk menarik dan membangkitkan minat konsumen yang potensial (Roque \& Raposo, 2016). Media sosial dapat menyediakan saluran komunikasi yang efektif dengan biaya yang relatif rendah dengan jangkauan global (Amaro et al., 2016).

Usaha kecil dan menengah (UKM) dianggap sebagai faktor kunci utama untuk pertumbuhan, inovasi, pekerjaan, inklusi sosial dan untuk menyediakan keberlanjutan ekonomi bagi masyarakat secara keseluruhan (Dumitriu et al., 2019). Fleksibilitas dan kemampuan beradaptasi sektor UKM adalah fitur utama untuk mengatasi krisis ekonomi dan sangat relevan dengan kondisi ekonomi saat ini.

Desa Pamulihan merupakan sebuah desa yang berlokasi di wilayah kecamatan Pamulihan Kabupaten Sumedang yang merupakan hasil pemekaran dari wilayah Desa Pamulihan yang luas. Berdasarkan data Kecamatan Pamulihan dalam Angka tahun 2014 yang dikeluarkan oleh Badan Pusat Statistik (BPS) Kabupaten Sumedang, pada tahun 2013 Desa Pamulihan memiliki status sebagai pedesaan dengan klasifikasi sebagai desa swadaya mula. Desa Pamulihan menghasilkan kerajinan tangan dari kayu yang memiliki kualitas yang sangat tinggi, seperti wayang golek dan cidera mata, akan tetapi pasarnya masih sangat terbatas. Di bidang pertanian, sektor perkebunan yang sudah maju yaitu Waida Farm yang terletak di RW 02 Kampung Lembang, yang membudi dayakan Talas, golden berry, manggis dan jambu Kristal, dimana mereka menjual buah segar dan juga mengolah buah menjadi selai dari golden berry.

\section{MASALAH}

Tingginya potensi yang dimiliki Desa Pamulihan ini dapat menjadikan masyarakat yang ada di daerah ini menjadi lebih sejahtera. Akan tetapi masih banyak permasalahan yang dihadapai oleh masyarakat Desa Pamulihan seperti pada uraian dibawah ini: 
a. Kurangnya permodalan untuk dapat mengembangkan usahanya

b. Terbatasnya kreatifitas masyarakat dalam mengembangkan produk

c. Rendahnya pengetahuan untuk dapat melakukan pemasaran dari produk yang dihasilkannya

\section{METODE}

Untuk mengatasi permasalahan yang ada, maka terdapat beberapa usulan kegiatan pengabdian kepada masyarakat yang bertujuan untuk meningkatkan kapasitas pengusaha serta pengrajin di Desa Pamulihan yaitu dengan kegiatan berikut ini:

a. Pelatihan pemanfataan platform digital untuk pemasaran produk

b. Pelatihan untuk merancang produk kreatif dan inovatif yang berkelanjutan

Kegiatan pelatihan ini menggunakan pendekatan metode pelatihan partisipatif. Yaitu dengan memberikan penyuluahn serta bimbingan praktek kepada para peserta pelatihan. Kegiatan ini akan memberikan praktik langsung kepada para pengusahan dalam mengimplementasikan fitur pemasaran digital dan perancangan produk yang inovatif untuk pengembangan bisnis masyarakat di Desa Pamulihan. Adapun tahapan dalam kegiatan tersebut adalah sebagai berikut:

a. Mengidentifikasi kondisi demografi penduduk di Desa Pamulihan

b. Mengidentifikasi potensi alam di Desan Pamulihan yang dapat dikembangkan menjadi produk yang inovatif dan kreatif

c. Mengadakan diskusi, wawancara dan observasi dengan para pengusaha di Desa Pamulihan

d. Melakukan analisis kebutuhan pelatihan

e. Merancang modul dan materi pelatihan

f. Melaksanakan kegiatan pelatihan

g. Melakukan evaluasi pelatihan

\section{HASIL DAN PEMBAHASAN}

\section{Pelatihan Pemasaran Digital untuk Produk Kerajinan Kayu}

Pengabdian kepada masyarakat di Desa Pamulihan yang pertama yaitu bertujuan untuk mengembangkan usaha kerajinan tangan dari kayu Desa Pamulihan guna meningkatkan pendapatan masyarakat Desa Pamulihan dan guna menjadikan Desa Pamulihan sebagai desa sentra pengrajin kayu. Harapan dari masyarakat pelaku usaha kerajinan sendiri ingin 
menjadikan Desa Pamulihan sebagai sentra kerajinan kayu yang dapat dikenal masyarakat lua serta adanya kemajuan dalam pemasaran. Adapun hasil kerajinan kayu yang dihasilkan oleh Desa Pamulihan yaitu wayang golek, alat musik berupa angklung dan calung, piala kayu, casing handphone dan masih banyak lagi.

\section{Gambar 1}

\section{Gambar Kerajinan Kayu di Desa Pamulihan}
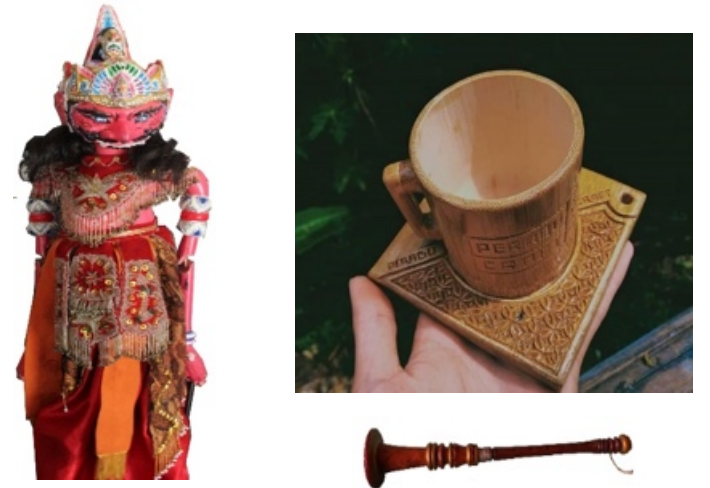

Pengabdian kepada masyarakat ini memberikan pelatihan berupa sosialisasi kepada para pengrajin kayu yang berusia lebih muda dalam pemanfaatan media sosial sebagai media yang cukup efektif untuk pemasaran produk kerajinan kayu. Pelatihan dilakukan dalam pengaplikasian situs hydro web untuk memasarkan produk lewat marketplace berupa website atau aplikasi online yang memfasilitasi proses jual beli dari berbagai toko. Pelaksanaan Training Digital Marketing dilatarbelakangi untuk membantu pengrajin dalam mengembangkan usahanya dan memperluas pangsa pasar.

Pembuatan website pada domain hydro web dan market place Bukalapak, diharapkan menjadikan produk pengrajin kayu dapat dikenal lebih luas di masyarakat global dan dengan harapan pengrajin kayu akan menghasilkan pendapatan yang lebih besar, keuntungan lain yaitu produk pengrajin mengalami perluasan segmentasi pasar, peningkatan penjualan dan pendapatan serta meningkatkan eksistensi Desa Pamulihan melalui sentra kerajinan kayu. Marketplace terkenal adalah karena terdapat kemudahan dan kenyamanan dalam penggunaannya. Marketplace dianggap sebagai sentra penjualan dimana terdapat banyak berbagai transaksi jual beli. Terdapat berbagai macam jenis dari marketplace di Indonesia yaitu produk, jasa, dan juga bursa tenaga kerja.

\section{Pelatihan Pengembangan Produk Inovasi}

\section{2a. Produk Inovasi Berbahan Dasar Talas}

Pelatihan berikutnya yaitu pelatihan mengenai pengembangan produk inovasi berbahan dasar talas sebagai salah satu hasil pertanian di Desa Pamulihan. Talas sendiri 
merupakan salah satu tanaman yang diproduksi diberbagai daerah di Indonesia terutama Desa Pamulihan, Kabupaten Sumedang. Potensi talas sangat besar dikembangkan di Desa Pamulihan karena produksinya cukup melimpah dan banyak ditanam oleh masyarakat. Tetapi kebanyakan hasil produksi talas digunakan untuk bahan konsumsi langsung dan tidak dijadikan produk melainkan di jual dalam kondisi mentah. Maka dari itu untuk meningkatkan nilai jual talas dengan dilakukannya inovasi berupa produk kecantikan bedak padat berbahan dasar talas. Ide pengembangan produk ini juga bermanfaat untuk meningkatkan pendapatan daerah, menyerap tenaga kerja apabila dikembangkan dalam skala besar. Talas memiliki banyak kandungan yang baik bagi kulit, namun tidak banyak orang yang menyadarinya. Pada era ini sudah ada banyak produk yang mengeluarkan bedak padat, namun masyarakat masih sering khawatir mengenai bahan kimia yang terkandung didalamnya. Maka dibuatlah bedak padat natural yang berbahan campuran talas.

\section{Gambar 2}

\section{Gambar Produk Inovasi Bedak Berbahan Dasar Talas}

\section{2b. Produk Inovasi Berbahan Dasar Daun Berry}

Pelatihan berikutnya yaitu pengembangan produk inovasi berbahan dasar daun berry yang juga merupakan hasil pertanian dari Desa Pamulihan. Golden berry atau lebih dikenal ciplukan (cecenet) merupakan buah berwarna kuning di dalam pembungkus seperti kertas yang berbentuk lentera. Buah ini mempunyai rasa yang khas yaitu manis sedikit seperti nanas, tetapi pahit ketika belum matang. Buah ini juga umumnya tumbuh liar dan dapat didapati bercampur dengan tanaman lainnya di kebun. Tetapi, saat ini tidak sedikit petani yang sengaja membudidayakan tanaman ini karena nutrisi tinggi yang terkadungnya membuat banyak orang mencari buah yang berumur pendek ini. Salah satu wilayah yang membudidayakan tanaman ciplukan ini adalah Desa Pamulihan, Kecamatan Pamulihan Kabupaten Sumedang. 


\section{Gambar 3}

\section{Gambar Golden Berry}

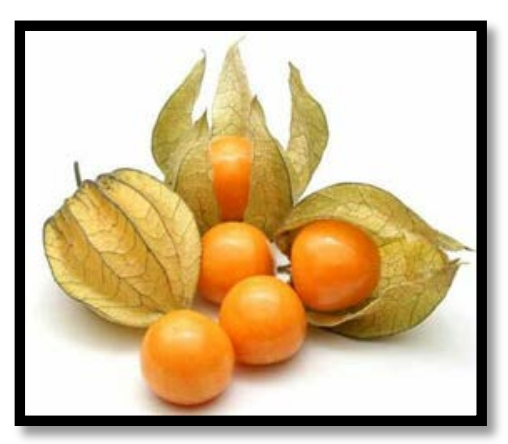

Daun golden berry memiliki banyak kandungan yang baik bagi kesehatan tubuh, namun masih banyak yang tidak menyadarinya. Maka sebagai alternatifnya, pelatihan ini memberikan gambaran mengenai pembuatan teh berbahan dasar daun ciplukan yang dapat dikonsumsi oleh siapa saja dari berbagai kalangan. Dimana selain memanfaatkan limbah produksi, produk ini juga memiliki banyak manfaat bagi konsumennya. Selain itu juga, pengembanan produk inovasi teh ini dapat berkontribusi dalam meningkatkan pertumbuhan ekonomi di Desa Pamulihan.

\section{KESIMPULAN}

Kegiatan pengabdian kepada masyarakat mengenai pemberdayaan masyarakat dalam upaya untuk meningkatkan taraf kehidupan melalui inovasi produk bebas bahan kimia berbahaya di Desa Pamulihan Kabupaten Sumedang, telah terlaksana dengan baik. Produk inovasi tersebut diantaranya yaitu produk kerajinan tangan, produk kecantikan bedak berbahan dasar talas dan teh herbal berbahan dasar daun berry.

Dari hasil survey dan kunjungan mengenai potensi wirausaha Desa Pamulihan, Wirausaha yang berpotensi untuk dikembangkan adalah yang pertama yaitu kerajinan kayu yang menghasilkan wayang golek dan handycraft dengan inovasi pembuatan wayang costum character dan variasi handycraft kayu yang banyak. Kendala-kendala yang di alami oleh para pengrajin diantaranya adalah sulitnya pemasaran hasil kerajinan kayu dikarenakan kerajinan kayu termasuk barang dengan peminat yang segmented.

Selain berpotensi dari segi kerajinan kayu, Desa Pamulihan juga berpotensi menghasilkan suatu produk berdasarkan hasil alam Desa Pamulihan itu sendiri, salah satunya yaitu Talas dan Daun Berry. Kegiatan pengabdian kepada masyarakat ini memberikan inovasi dalam pembuatan produk kecantikan berupa bedak yang berbahan dasar talas, sehingga produk ini bebas dari bahan kimia berbahaya. Kemudian produk inovasi yang kedua yaitu 
produk teh herbal yang berasal dari daun berry, yang merupakan hasil alam dari Desa Pamulihan.

\section{DAFTAR PUSTAKA}

Alalwan, A. A., Rana, N. P., Dwivedi, Y. K., \& Algharabat, R. (2017). Social media in marketing: A review and analysis of the existing literature. Telematics and Informatics, 34(7), 1177-1190.

Amaro, S., Duarte, P., \& Henriques, C. (2016). Travelers' use of social media : A clustering approach. Annals of Tourism Research, 59, 1-15.

Bouwman, H., Nikou, S., Molina-Castillo, F. J., \& de Reuver, M. (2018). The impact of digitalization on business models. Digital Policy, Regulation and Governance, 20(2), 105-124.

Bruhn, M., Schoenmueller, V. and Schäfer, D.B. (2012), "Are social media replacing traditional media in terms of brand equity creation?”, Management Research Review, Vol. 35 No. 9, pp. 770-790.

Dumitriu, D., Militaru, G., Deselnicu, D. C., Niculescu, A., \& Popescu, M. A. M. (2019). A Perspective Over Modern SMEs: Managing Brand Equity, Growth and Sustainability Through Digital Marketing Tools and Techniques. Sustainability, 11(7), 2111.

Kaplan, A.M. and Haenlein, M. (2010), "Users of the world, unite! The challenges and opportunities of social media”, Business Horizons, Vol. 53 No. 1, pp. 59-68.

Lister, M. (2018). 40 essential social media marketing statistics for 2018. Retrieved fromhttps://www.wordstream.com/blog/ws/2017/01/05/social-media-marketingstatistics.

Malhotra, A., Kubowicz Malhotra, C. and See, A. (2013), "How to create brand engagement on facebook”, MIT Sloan Management review, Vol. 54 No. 2, pp. 18-20.

Moore, G. A. (1993). Crossing the chasm: Marketing and selling technology project. Harper Collins.

Pickard-Whitehead, G. (2018). 20 amazing instagram statistics small business owners must see. Retrieved fromhttps://smallbiztrends.com/2018/05/instagram-statistics-smallbusiness.html. 
Roque, V., \& Raposo, R. (2016). Social media as a communication and marketing tool in tourism: An analysis of online activities from international key player DMO. Anatolia, 27(1), 58-70.

Taiminen, H. M., \& Karjaluoto, H. (2015). The usage of digital marketing channels in SMEs. Journal of Small Business and Enterprise Development, 22(4), 633-651. 